Revista de Investigación Universitaria, 2015, Vol. 4 (2): 33-43

ISSN: 2312-4253 (Versión impresa) ISSN: 2078-4015 (Versión digital)

\title{
Calidad fisicoquímica, microbiológica y toxicológica de leche cruda en las cuencas ganaderas de la región Puno -Perú
}

\section{Physicochemical, microbiological and toxicological quality of raw milk in the cattle basins of the Puno-Peru region}

\author{
Brousett-Minaya, Magalya; Torres Jiménez, Ana ${ }^{\mathrm{b}}$; Chambi Rodríguez, Alex ${ }^{\mathrm{c}}$; Mamani Villalba, Bethy ${ }^{\mathrm{d}} \mathrm{y}$ \\ Gutiérrez Samata, Hernán ${ }^{\mathrm{e}}$ \\ a,c,dEP Ingeniería Ambiental, Facultad de Ingeniería y Arquitectura, Universidad Peruana Unión, FJ \\ bEP de Ingeniería de Industrias Alimentarias, Facultad de Ingeniería y Arquitectura, Universidad Peruana \\ Unión, FJ e Dirección de desarrollo agrícola y medio ambiente. Proyecto Especial Binacional Lago Titicaca - \\ PELT, Ministerio de Agricultura, Puno - Perú \\ Recibido 8 de setiembre del 2015-Aceptado 14 de noviembre del 2015
}

\begin{abstract}
Resumen
El objetivo del presente trabajo fue evaluar la calidad de la leche cruda en cuanto a sus propiedades fisicoquímicas, microbiológicas y toxicológicas, en siete cuencas representativas de la región Puno. Los resultados fueron comparados con los estándares establecidos en la Norma Técnica Peruana para leche y productos lácteos NTP 200.001-2003 y con la Norma Oficial Mexicana NOM-155-SCFI-2012 para los parámetros de proteína y lactosa en ausencia de parámetros peruanos. Para la caracterización fisicoquímica se determinó pH, acidez, densidad, contenido de grasa, proteína, lactosa, sólidos totales y sólidos no grasos; también se realizaron análisis microbiológicos de E. Coli y mesófilos. Del mismo modo, el estudio abarcó el análisis de residuos de pesticidas como son organoclorados, organofosforados, carbamatos y piretroides en concentración de 1,0 ug/g de muestra, los cuales dieron resultados negativos para los cuatro grupos de pesticidas; las determinaciones fisicoquímicas en más del 50\% de las cuencas (a excepción de acidez y pH) se encontraron dentro de los estándares de la NTP y la NOM. La presencia de mesófilos, en su mayoría, fueron encontrados dentro de los parámetros establecidos, a excepción de dos cuencas lecheras y en cuanto a E. Coli ninguna cuenca cumplió con las normas establecidas, encontrándose una leche de baja calidad higiénica.
\end{abstract}

Palabras clave: Leche, calidad fisicoquímica, microbiológica, productores, pesticidas.

\begin{abstract}
The objective of the present work was to evaluate the quality of raw milk in terms of its physicochemical, microbiological and toxicological properties in seven basins representative of the Puno region. The results were compared with the standards established in the Peruvian Technical Standard for milk and milk products NTP 200.001-2003 and with the official Mexican Standard NOM-155-SCFI-2012 for the parameters of protein and lactose in the absence of Peruvian parameters. For the physicochemical characterization $\mathrm{pH}$, acidity, density, fat content, protein, lactose, total solids and non-fatty solids were determined; Microbiological analyzes of E. coli and mesophils were also performed. In the same way the study covered the analysis of pesticide residues such as organochlorines, organophosphates, carbamates and pyrethroids in a concentration of $1.0 \mathrm{ug} / \mathrm{g}$ of sample, which gave negative results for the four groups of pesticides, physico-chemical determinations in more than $50 \%$ of basins (except for acidity and $\mathrm{pH}$ ) were found to meet the NTP and NOM standards. The presence of mesophiles were mostly found within the parameters established with the exception of two milk basins and for E. coli no basin complied with the established standards, and milk of low hygienic quality was found.
\end{abstract}

Keywords: Milk, physicochemical quality, microbiological, producers, pesticides.

Correspondencia al autor:

email: investigacion.proyectos@upeu.pe 


\section{Introducción}

La calidad de la leche es un aspecto fundamental en la competitividad de la ganadería vacuna lechera, asimismo es insustituible en la alimentación de las personas perteneciendo a la canasta básica familiar, por tanto, su inocuidad es importante como prioridad de la salud pública. Un estudio de la Organización de las Naciones Unidas para la Alimentación y la Agricultura (FAO) sobre la situación de la lechería en América Latina y el Caribe en 2011, reportó que de los 19 países de América Latina, el Perú se encuentra en el noveno lugar de producción lechera con aproximadamente 100 mil productores, lo que permite estar en el séptimo lugar de productores de los países evaluados (FEPALE, 2011). La producción de leche en el Perú creció ininterrumpidamente desde el año 2001 registrándose en el período 2005 al 2013, un aumento de producción de 1,2 millones de toneladas a 1,8 millones de toneladas al año. Del mismo modo, para el año 2014, Puno sube al cuarto lugar de producción nacional con 7,5\% atrás de Arequipa $(17,4 \%)$, Cajamarca $(17,2 \%)$ y Lima $(16,9 \%)$. Según MINAGRI (2014), el 69,3\% de la producción de leche fresca de vaca se ubica en: Arequipa $(17,4 \%)$, Cajamarca (17,2\%), Lima (16,9\%), Puno (7,4\%), La Libertad (5,9\%) y Cusco (5,8\%).

La región Puno se encuentra ubicada en la zona Sur-Oriental del Perú, cuenta con una extensión territorial de $71,999.00 \mathrm{~km}^{2}$, constituyendo el 6\% del territorio nacional, la actividad ganadera se desarrolla en varias zonas geográficas, pero la de mayor cantidad se aprecia en la zona agro-ecológica Suni (baja y alta) con altitudes que oscilan entre 3,830 y 4,000 m.s.n.m entre los lados occidentales y orientales de ambas cordilleras. Esta zona presenta una topografía relativamente plana o mediamente accidentada y de mayor prosperidad para la ganadería, destacando las especies como bovinos, ovinos y los camélidos sudamericanos. (Plan de la competitividad cadena productiva de productos lácteos, 2014). La producción lechera, en esta región, ha ido en aumento considerable desde el año 2005 reportando, en ese año, 44154 t y llegando a 71542 t en el 2009; del mismo modo, Puno duplicó su producción de leche en el 2013, llegando a 420 mil litros por día (Proyecto Pradera, 2013) y, en este mismo año, se reportó una producción de 79,0 t. Asimismo, los animales en ordeño que tiene Puno representa el 13\% del total nacional (PELT, 2012).

Para seguir impulsando el incremento de producción de leche en esta región, el Proyecto Especial Binacional Lago Titicaca (PELT), órgano dependiente del
Ministerio de Agricultura, se propone como objetivo impulsar el mejoramiento genético, poniendo en práctica la inseminación artificial con el fin de mejorar la productividad ganadera, este proyecto monitorea y asesora a diferentes cuencas lecheras que son: Mañazo, Vilque, Acora, Ilave, Cabanillas, Cabanilla, Cabana Ayaviri y Azángaro, de las cuales siete han sido consideradas en este estudio. La producción lechera varía en el año según los cambios climatológicos existentes, en los meses de junio a agosto, donde la temperatura desciende hasta $-20 \mathrm{oC}$, la producción de leche disminuye considerablemente, siendo su rendimiento por hato por día en época seca de 18,4 litros y en época de lluvias de 28,4 litros. La producción de leche promedio, en época seca por vaca, es de 5,05 litros y en época de lluvias es de 8,34 litros (PELT, 2012). El 37\% de los productores crían animales cruzados entre ganado vacuno criollo y Brown swiss, el $61 \%$ se dedica a la crianza de ganado Brown swiss, el $2 \%$ cría otras razas, la más representativa es Holstein. La alimentación del ganado se basa, principalmente, en pastoreo de praderas nativas, pastos naturales desarrollados entre 3,815 y 4,200 m.s.n.m, siendo el recurso que posee una abundante riqueza de especies forrajeras (gramínea, ciperácea, leguminosa, juncácea). La vegetación dominante está representada por la Festuca dolichophylla (“chilligua”), que están asociados a Festuchetum y Mulember- getum denominados "chilliguares” y "gramales", los cuales son muy palatables para el ganado, un mínimo porcentaje de los ganaderos (7,96\%) utiliza ensilado, el ganado que produce mayor a 8lt de leche por día son alimentados con $1 \mathrm{~kg}$ de heno de avena por día para mejorar su producción lechera (PELT, 2012).

La producción de leche se vende a pequeñas agroindustrias locales procesadora de lácteos, queserías artesanales, otro destino es para la industria (venta a la empresa Leche Gloria) y otra no menos importante se comercializa mediante intermediarios (venta directa al porongueo), quienes la recolectan directamente de la unidad de producción para, posteriormente, llevarlas y comercializarlas en mercados a venta directa al público, sin ningún tratamiento previo. Los productos lácteos como el queso puneño son reconocido y posicionado en los diferentes mercados a nivel nacional (Cusco, Arequipa, Lima) y local (Puno, Juliaca Ayaviri). (Plan de la cadena productiva de productos lácteos). La calidad de leche es un aspecto fundamental en la competitividad de la ganadería vacuna lechera y, para su consumo garantizado, debe estar exento de microorganismos, agentes patógenos y sustancias tóxicas como los pesticidas. La actividad agrícola es la 
que consume en mayor cantidad los plaguicidas, por lo que se considera que este sector productivo es el de mayor exposición a estos contaminantes (Pitarch et al., 2001; Waliszewski e Infanzón 2003; Hernández et al., 2007), los cuales al ser aplicados a los diferentes cultivos son arrastrados a otros campos, según las condiciones climáticas (viento, lluvia, temperaturas altas), las causas fundamentales de la presencia de residuos de plaguicidas organoclorados en la leche son sus propiedades fisicoquímicas de persistencia, liposolubilidad y bioacumulación, así como el uso excesivo de estos compuestos en las prácticas agropecuarias (Pinto et al., 1990a) y el uso en el control de enfermedades transmitidas por insectos vectores (Dhaliwal, 1990; Rodríguez et al., 1994 ; Hernández y Pérez, 1995).

Estas actividades antropogénicas han traído como consecuencia la contaminación de los sustratos bióticos y abióticos, ya que al dispersarse entran a las cadenas tróficas donde se bioacumulan y el ganado, expuesto a estos sustratos, elimina residuos de plaguicidas o algún derivado de su biotransformación en la leche. Según Medina (2010) el consumo de alimentos, con residuos de estos compuestos, causan alteraciones en los diferentes sistemas del cuerpo humano, como en el reproductivo y el inmunológico, también se encontraron evidencias de enfermedades como el cáncer de páncreas (Goutner et al., 2001) y enfermedades de la tiroides (Langer, 2003).

El Perú suscribió el Convenio de Estocolmo sobre Contaminantes Orgánicos Persistentes (COPs) (Plan nacional de implementación del convenio de Estocolmo sobre los COPs, 2006) donde prohíbe el uso de doce plaguicidas organoclorados, entre ellos Aldrín, Dieldrín, Endrín, Heptacloro, HCB, Clordano, Toxafeno Mirex y DDT, este último ha sido restringido en varios países debido a su potencial para causar cáncer y problemas reproductivos (Fernícola, 1985; López, 1996). El DDT presenta persistencia en suelo y sus respectivos factores de bioconcentración, pudiendo permanecer hasta 30 años seguidos del Aldrín por 6 años y beta HCH por 3 años; aunque los productos de degradación hayan perdido su acción pesticida, pueden seguir siendo nocivos para la salud y el equilibrio ambiental (Weber, 1997). El grupo de plaguicidas organofosforados cobra importancia después de la prohibición de los plaguicidas organoclorados y han resultado ser muy eficientes y económicos en el control de plagas (Juan et al., 2003). Los plaguicidas más utilizados son clorpirifos, diazinon, metil paratión, malatión, profenofos y etión; estos son apli- cados contra una amplia serie de insectos y gorgojos, especialmente en cultivos de algodón, maíz, trigo, legumbres y papa (Murcia y Stashenko, 2008). Algunos, como el diclorvos, se administran oralmente en el ganado para el control interno de parásitos, y otros son usados externamente para controlar parásitos sobre la piel del animal (Fong et al., 1999). Los plaguicidas con denominación común como el "Karate y Primor” pertenecen al grupo de los piretroides y carbamatos, estas sustancias son empleadas principalmente para combatir las plagas en vegetales como el brócoli (Pérez et al., 2009). En el año 2006 se dio a conocer que los COPs y otros plaguicidas prohibidos son muy comunes en diversas regiones del país; sobre todo en la costa norte y centro (Piura, Chiclayo y Lima), Selva (Iquitos y Tarapoto) y sierra central y sur (Huancayo y Puno) (Inventario Nacional de Plaguicidas COP. 2006).

En vista de la importancia de la leche en esta región, el propósito de este trabajo es el estudio de la calidad de leche producida en importantes cuencas lecheras de Puno, verificando la existencia de contaminación de plaguicidas, así como la calidad fisicoquímica y microbiológica de la leche en base a la Norma Técnica Peruana NTP 202.001.2003 y la Norma Oficial Mexicana NOM 155-SCFI 2012.

\section{Método}

\section{Zona de estudio}

Se seleccionaron siete zonas productoras de leche monitoreadas por el PELT, las cuales están ubicadas geográficamente, como muestra en la Tabla 1.

Tabla 1

Zonas de producción lechera

\begin{tabular}{|c|c|c|c|}
\hline Distrito & $\begin{array}{c}\text { Altitud } \\
\text { m.s.n.m. }\end{array}$ & Latitud Sur & $\begin{array}{c}\text { Longitud } \\
\text { Oeste }\end{array}$ \\
\hline Ilave & 3847 & 16’05’03’’ & 69’38’03”' \\
\hline Acora & 3867 & 15’58’89”' & 69’47’49”' \\
\hline Mañazo & 3926 & $15^{\prime} 47^{\prime} 54^{\prime \prime}$ & 70 '20’28”' \\
\hline Vilque & 3860 & $15^{\prime} 45^{\prime} 48^{\prime \prime}$ & 70’15’19”' \\
\hline Cabanillas & 3885 & 15’38’14”' & 70’20’39” \\
\hline Azángaro & 3559 & 14'54’24'” & 70'11'36” \\
\hline Ayaviri & 3918 & 14’52’55”' & $70^{\prime} 35^{\prime} 24^{\prime \prime}$ \\
\hline
\end{tabular}

Fuente: INEI - Censos Nacionales 2007: XI de Población y VI de Vivienda.

La localidad de Azángaro representa una de las zonas con mayor producción lechera, de la cual se escogieron 2 cuencas más representativas, que son Yanama- 
yo y Progreso denominados en este estudio Azángaro 1 y Azángaro 2 respectivamente.

\section{Recolección de la muestra}

El estudio se realizó en los meses de agosto y setiembre (época seca) del 2014, donde la temperatura fluctuó entre 16 y $20^{\circ} \mathrm{C}$. Las zonas en estudio fueron: Azángaro 1, Azángaro 2, Ayaviri, Ilave, Mañazo, Vilque, Acora y Cabanillas. La actividad de ordeño libre (solo a mano) se realiza dos veces al día, la muestra de leche se tomó una vez concluida el ordeño en la mañana directamente de los recipientes de almacenamiento, la temperatura de la leche varió entre 20 y $22^{\circ} \mathrm{C}$. Las muestras en volumen de $800 \mathrm{ml}$ fueron almacenadas en recipientes de vidrio esterilizado y colocados en cámara fría a una temperatura de $4^{\circ} \mathrm{C}$. Un volumen de $400 \mathrm{ml}$ fue destinado al laboratorio de toxicología de la Universidad Nacional Mayor de San Marcos "CICOTOX" donde se desarrolló el análisis de Organoclorados, Organofosforados, Carbamatos y Piretroides de las muestras en estudio. Los análisis fisicoquímicos y microbiológicos fueron realizados en los laboratorios de Química y Microbiología Ambiental de la Universidad Peruana Unión.

\section{Análisis fisicoquímicos}

A cada una de las muestras se les determinaron los parámetros fisicoquímicos por duplicado. Para determinación de acidez se realizó mediante titulación alcalimétrica según el método AOAC 947.05 que consiste en titulación de una alícuota de $9 \mathrm{ml}$ de muestra, utilizando como valorante $\mathrm{NaOH} 0,1 \mathrm{~N}$ y como indicador la fenolftaleína. Los cálculos son expresados en gramos de ácido láctico por 100ml de leche. El extracto seco total o sólidos totales por el método de estufa modificado AOAC 925.23, basado en la desecación de la leche, la cual es sometida a una temperatura constante de $102^{\circ} \pm 20 \mathrm{C}$ en estufa de desecación. Los cálculos de \% de extracto seco fueron determinados por diferencias de peso. El porcentaje de proteínas por el método de Kjeldahl AOAC 928.08, basado en la digestión ácida de la muestra con catalizadores de sulfato de cobre y potasio, seguida de una destilación de amoníaco recogido en solución de ácido bórico y finalmente la retrovaloración del ión borato con $\mathrm{HCl}$ $0.1 \mathrm{~N}$ con indicador mixto. La determinación de nitrógeno, posteriormente fue calculado a porcentaje de proteína. La densidad de la leche se determinó con un lactodensímetro QUEVENNE graduado, AOAC 925.22 (Helrich, 1990). El pH y la temperatura fue determinada por potenciómetro HANNA HI 98129.
El contenido de grasa y lactosa se determinó mediante un medidor ultrasónico (Lactoscan MCC). Equipo basado en espectroscopía ultrasónica, utilizando 100 $\mathrm{ml}$ de muestra para cada análisis, el mismo procedimiento que se realizó en el estudio para la determinación de grasa y proteínas de leche en Colombia (Gomez et al., 2014).

\section{Análisis microbiológico}

El conteo total de bacterias mesofílicas aerobias se realizó mediante la técnica de recuento en placa a 30 ${ }^{\circ} \mathrm{C}$, cada muestra de leche se calentó a $30{ }^{\circ} \mathrm{C}$ y se agitó en forma de arcos, para asegurar una distribución homogénea de los microorganismos. Una vez mezclada se prepararon tres diluciones por muestra $\left(10^{-1}, 10^{-3}\right.$ y $\left.10^{-5}\right)$ por triplicado, para sembrarse en placas Petri y obtener con esto placas con una cuenta total entre 10 y 100 colonias. Una vez que se prepararon las diluciones, se adicionó a cada placa $1 \mathrm{ml}$ de muestra y de $10^{-12} \mathrm{ml}$ de medio de cultivo "plate count agar” fundido a una temperatura de $45^{\circ} \mathrm{C}$, se dejaron secar hasta que solidificaran y, posteriormente, se invirtieron y se pasaron a una estufa para incubarlas a $30{ }^{\circ} \mathrm{C}$ x $24 \mathrm{~h}$. El conteo de cada placa se efectuó en el contador de colonias MERCK para el cálculo respectivo de microorganismos por mililitro. La metodología empleada para E. Coli solo fue por variante de medio de cultivo, utilizando agar "Mackonkey" e incubando la muestra a $27^{\circ} \mathrm{C}$ de 18 a $24 \mathrm{~h}$.

\section{Residuos de pesticidas}

La metodología utilizada fue de cromatografía de capa fina (CCF). Los plaguicidas en estudio como son los organoclorados, organofosforados, carbamatos y piretroides, se desplazan en una dirección predeterminada por medio de un material sólido insoluble inorgánico que es silicagel G60 como fase estacionaria y la fase móvil por una mezcla de solventes de hexano: acetona: alcohol isopropílico, los cuales migran a través de la superficie de la placa. La fase móvil arrastra a los plaguicidas por un proceso de reparto múltiple que se da en toda sustancia según su polaridad. Las muestras fueron tratadas con mezcla de hexano: acetona en proporción 1:1, después de ser agitadas se dejaron en reposo y posteriormente filtradas. La extracción se realizó con éter etílico con agitación en pera de extracción, la fase etérea fue evaporada a sequedad en baño maría ( 40 a $60^{\circ} \mathrm{C}$ ) hasta la obtención de residuo, el cual fue disuelto en hexano para la corrida en la cromatografía. 


\section{Resultados y Discusión}

De acuerdo a la evaluación fisicoquímica de leche producida en la región Puno, en su mayoría, se encuentra dentro de los valores considerados como aceptable para leche cruda de vaca según la NTP 201.001.2003 a excepción de la acidez (Tabla 2). El contenido de proteínas guardan similitud por los reportados de Hernández y Ponce (2002) para Cuba con razas de Holstein Friesian los cuales varían entre 2,9 y 3,05\%), de igual manera los estudios realizados en dos estados de México (Bernal et al., 2007) reportando entre 3,0 y 3,19\% de proteína y 4,5 y 4,6\% de lactosa que son similares con los registrados en la región Puno manifiestos en la Tabla 3, sin embargo, las cuencas de Azángaro 2, Cabanillas, Vilque y Acora reportaron un porcentaje de proteínas bajo, inferior a la norma $(3,0 \%)$, lo cual tiene relación con los resultados de lactosa, siendo las cuatro cuencas señaladas como las más bajas en porcentaje de esta proteína (4,17; 4,22; 4,54 y 4,45\% respectivamente). La cantidad de proteína en leche cruda tiene mayor realce en Arequipa según fue reportado por Mamani (2009) donde los resultados fueron de 3,06 y 3,39\% en las cuencas de Majes variando estas concentraciones según la época del año, estas diferencias podrían deberse a que estos últimos son alimentados con concentrados proteicos derivados de harina de pescado, soya, alfalfa y maíz para forraje tal como lo señala Flores (2001) y Zegarra (2007), mientras el ganado de Puno es alimentado mediante pastoreo natural y, en las épocas de heladas, con poca cantidad de ensilados los cuales no son elaborados por la mayoría de ganaderos. Los resultados de grasa en cinco cuencas cumplen con la NTP, siendo la cuenca de Ayaviri la que presenta mayor porcentaje de grasa $(3,60 \%)$ resultado similar a la reportada en el ganado de Holstein en Cuba reportando un 3,62\% de grasa (Hernández y Ponce, 2002). Las cuencas de Cabanillas, Azángaro 1 y 2 perciben una disminución en este parámetro de 3,10; 3,09 y 3,18\% respectivamente. Gallardo (2003) sugiere que se pueden observar bajos niveles de grasa en leche debido a altas concentraciones de fibra, pero se trata de una fibra que es de lenta degradación en el rumen, lo que disminuye su disponibilidad para la síntesis de ácidos grasos, los subproductos agroindustriales provocan un descenso de contenido graso, debido a que la fermentación en el rumen es defectuosa y disminuye la producción de ácido acético y otros ácidos volátiles, principalmente formadores de ácidos grasos, así también fue explicado por Spreer (1991); Yamandú (2002); Santos (1998) y Arriaga (1996).

Tabla 2

Promedio y desviación estándar (DE) de los análisis físicoquímicos en las cuencas lecheras de Puno

\begin{tabular}{lccccc}
\hline Cuencas & $\begin{array}{c}\text { Densidad } \\
\text { g/ml }\end{array}$ & DE & pH & $\begin{array}{c}\text { Acidez } \\
\text { g/100 }\end{array}$ & DE \\
\hline Vilque & 1,029 & 0,001 & 6,82 & 0,198 & 0,02 \\
Mañazo & 1,031 & 0,001 & 6,63 & 0,191 & 0,02 \\
Azángaro 1 & 1,032 & 0,002 & 6,40 & 0,189 & 0,01 \\
Azángaro 2 & 1,028 & 0,002 & 5,64 & 0,146 & 0,02 \\
Cabanillas & 1,027 & 0,011 & 6,72 & 0,155 & 0,01 \\
Ayaviri & 1,029 & 0,001 & 6,55 & 0,172 & 0,01 \\
Acora & 1,028 & 0,002 & 6,50 & 0,185 & 0,01 \\
Ilave & 1,032 & 0,015 & 6,81 & 0,199 & 0,03 \\
\hline NTP 202.001.2003 & $1,029-1,034$ & & & $0,14-0,16$ & \\
\hline
\end{tabular}


Brousett-Minaya, M.; Torres A.; Chambi, A.; Mamani, B. y Gutiérrez, H.

Tabla 3

Promedio y desviación estándar del análisis nutrimental de la leche en las cuencas lecheras de Puno

\begin{tabular}{|c|c|c|c|c|c|c|c|c|}
\hline Cuencas & $\begin{array}{c}\text { Sólidos no } \\
\text { Grasos } \\
\text { (g/100) }\end{array}$ & $\begin{array}{l}\text { Sólidos } \\
\text { Totales } \\
\text { (g/100) }\end{array}$ & $\begin{array}{l}\text { Grasa } \\
\text { (g/100) }\end{array}$ & $\begin{array}{c}\text { DE* } \\
\text { Grasa }\end{array}$ & $\begin{array}{c}\text { Proteína } \\
\text { (g/100) }\end{array}$ & $\begin{array}{c}\text { DE } \\
\text { Proteína }\end{array}$ & $\begin{array}{c}\text { Lactosa } \\
\text { (g/100) }\end{array}$ & $\begin{array}{c}\mathrm{DE} \\
\text { Lactosa }\end{array}$ \\
\hline Vilque & 8,26 & 12,82 & 3,49 & 0,21 & 2,95 & 0,15 & 4,54 & 0,19 \\
\hline Mañazo & 8,24 & 12,65 & 3,34 & 0,23 & 3,13 & 0,17 & 4,62 & 0,19 \\
\hline Azángaro 1 & 8,29 & 12,70 & 3,09 & 0,23 & 3,37 & 0,16 & 4,56 & 0,17 \\
\hline Azángaro 2 & 7,58 & 11,61 & 3,18 & 0,20 & 2,87 & 0,17 & 4,17 & 0,18 \\
\hline Cabanillas & 7,68 & 11,68 & 3,10 & 0,22 & 2,81 & 0,15 & 4,22 & 0,17 \\
\hline Ayaviri & 8,34 & 12,65 & 3,60 & 0,22 & 3,05 & 0,17 & 4,59 & 0,19 \\
\hline Acora & 8,04 & 12,48 & 3,32 & 0,21 & 2,95 & 0,16 & 4,45 & 0,18 \\
\hline Ilave & 8,74 & 12,63 & 3,38 & 0,23 & 3,20 & 0,15 & 4,80 & 0,19 \\
\hline NTP 202.001.2003 & $\min 8,20$ & $\min 11,40$ & $\min 3,20$ & & & & & \\
\hline NOM- 155-SCFI-2012 & & & & & $\min 3,0$ & & $4,3-5,2$ & \\
\hline
\end{tabular}

* Desviación estándar.

Los resultados de grasa en cinco cuencas cumplen con la NTP, siendo la cuenca de Ayaviri la que presenta mayor porcentaje de grasa $(3,60 \%)$ resultado similar a la reportada en el ganado de Holstein en Cuba, reportando un 3,62\% de grasa (Hernández y Ponce, 2002). Las cuencas de Cabanillas, Azángaro 1 y 2 perciben una disminución en este parámetro de 3,10; 3,09 y 3,18\% respectivamente. Gallardo (2003) sugiere que se pueden observar bajos niveles de grasa en leche debido a altas concentraciones de fibra, pero se trata de una fibra que es de lenta degradación en el rumen, lo que disminuye su disponibilidad para la síntesis de ácidos grasos, los subproductos agroindustriales provocan un descenso de contenido graso, debido a que la fermentación en el rumen es defectuosa y disminuye la producción de ácido acético y otros ácidos volátiles, principalmente formadores de ácidos grasos, así también fue explicado por Spreer (1991); Yamandú (2002); Santo (1998) y Arriaga (1996).

Los resultados de los sólidos totales para todas las cuencas se encuentran dentro de los parámetros establecidos con un mínimo de 11,4 g / 100, esto podría explicar los bajos niveles de rendimiento de leche en épocas secas, tal como lo explica Preston (1987) y Chamberlain (2002) que a menores rendimientos de leche la concentración de grasa y proteína es mayor, esto se evidencia en el presente estudio al observar la relación directa entre la concentración de grasa y solidos totales. La Federación Panamericana de Lechería FEPALE señala que la Grasa y la Proteína son los dos componentes sólidos utilizados mundialmente para determinar el valor de la leche, ya que son los compuestos que realmente tienen valor para la industria. Bajo este contexto podríamos decir que los valores encontrados para sólidos totales confirman el potencial industrial, principalmente en las cuencas de Vilque Mañazo y Azángaro 1 (12,82\%; 12,65\% y 12,7\% de sólidos totales respectivamente). Estos resultados tienen relación con la producción del sector artesanal y semiindustrial que procesa y transforma lácteos. Las plantas queseras se encuentran ubicadas, en su mayoría, en las cuencas lecheras de Melgar, quienes producen el $46 \%$ de leche de toda la región, le siguen Azángaro con el 35\% y Puno con la cuenca lechera de Mañazo (PELT, 2012). Por otro lado, también se evidencia el alto consumo y demanda de los quesos de esta región en los mercados locales (ciudades de Puno, Juliaca y Ayaviri) y nacionales (Arequipa y Lima), aunque la calidad no sea la esperada (Plan de implementación de la cadena productiva de productos lácteos, 2014).

La leche puede ser clasificada según su calidad basándose en la Norma Mexicana NMX-F-700-COFOCALEC-2004, que establece tres categorías: clases A, B y $\mathrm{C}$, que se encuentran en función del contenido de grasa y proteína. La clase A debe contener $>32 \mathrm{~g} / \mathrm{L}$ y más de $31 \mathrm{~g} / \mathrm{L}$, la clase $\mathrm{B}$, mínimo $31 \mathrm{~g} / \mathrm{L}$ y de $30 \mathrm{a}$ 30,9 g/L, y la clase C, un mínimo de $30 \mathrm{~g} / \mathrm{L}$ y de 28 a $28,9 \mathrm{~g} / \mathrm{L}$ de grasa y proteína respectivamente, de acuerdo a estos lineamientos la leche que se produce en la región Puno, en cuanto a grasa de cinco cuencas lecheras como son: Vilque, Mañazo, Acora, Ilave 
y Ayaviri pueden ser clasificadas de clase A, ya que cumple con el estándar mayor a $32 \mathrm{~g} / \mathrm{L}$, mientras que las cuencas de Azángaro 2 y Cabanillas son clasificadas de clase B, la leche proveniente de Azángaro 1, es clasificada de clase $\mathrm{C}$ por ser menor a $31 \mathrm{~g} / \mathrm{L}$ en grasa. En cuanto a proteína las cuencas de Mañazo, Azángaro 1 e Ilave son clasificadas de clase A por contener concentraciones $\geq 31 \mathrm{~g} / \mathrm{L}$, la cuenca de Ayaviri de clase $\mathrm{B}$ y las restantes de clase $\mathrm{C}$.

La densidad y pH son similares a los reportados por Álvarez-Fuentes (2012) en la calidad de leche cruda en México a excepción de las cuencas de Vilque, Ilave y Mañazo que reportaron valores de $\mathrm{pH}$ altos (6,82; 6,81 y 6,63 respectivamente), estos valores tienen relación con la alta acidez mayores a 0,19g/100 de ácido láctico. Las diferencias de $\mathrm{pH}$ y los valores elevados de acidez encontradas en este estudio se podrían deberse al efecto de la temperatura (llegando a $20^{\circ} \mathrm{C}$ ) por tanto la leche tiende a acidificarse, teniendo en cuenta que esta queda expuesta en el recipiente contenedor durante un tiempo prolongado hasta el término del ordeño y no existe un proceso de enfriamiento, ni ningún otro.

\section{Análisis microbiológico}

El recuento de bacterias Mesofílicas Aerobias y E. Coli permite valorar la calidad higiénica de la leche, estos parámetros están directamente relacionados con los factores de calidad del agua utilizada en la explotación lechera, la higiene en el ordeño, la limpieza del personal ordeñador, el lavado de los equipos y utensilios que están en contacto con la leche y el enfriamiento de la misma (NMX-F-700-COFOCALEC-2004), según la NTP una leche cruda aceptable puede contener hasta 1,0 x $106 \mathrm{ufc} / \mathrm{ml}$ (1000 000ufc/ $\mathrm{ml}$ ) en bacterias mesofílicas. Los resultados muestran que las cuencas de Mañazo, Azángaro 1, Azángaro 2, Cabanillas, Acora e Ilave se encuentran dentro de los estándares establecidos (7,0 x105; 6,0x105; 3,3x105; 7,3x105; 6,0x105 y 3,3x105 ufc/ml respectivamente), mientras las cuencas de Vilque y Ayaviri presentan 2,15 x107 y 1,43 x 107 ufc/ml respectivamente (Figura 1). Estos resultados demuestran que no se tiene buena calidad higiénica en estas dos últimas cuencas, esto se ratifica con la presencia de E. coli en cantidades abundantes, según la NTP la numeración máxima de coliformes expresadas ufc/ml es de 1000, lo cual indica que la calidad higiénica de leche de las ocho cuencas en estudio es muy baja, ya que ninguna se encuentra dentro de la norma estipulada.
La cuenca lechera, con más baja cantidad microbiana, es de Cabanillas con 1333 ( \pm 0.57) ufc/ml, seguida de Progreso 1(Yanamayo) con $2000( \pm 1.69) \mathrm{ufc} / \mathrm{ml}$, las dos cuencas más altas en contenido microbiano son las de Vilque y Ayaviri (Figura 2), con 149660 $( \pm 25.81) \mathrm{ufc} / \mathrm{ml}$ y $43000( \pm 3.6055) \mathrm{ufc} / \mathrm{ml}$ respectivamente. Estos valores microbianos altos se deben a dos vías principales: La vía mamaria y el medio externo (Pinzon, 2004), por la vía mamaria los microorganismos alcanzan la ubre pudiendo contaminar la leche antes o después del ordeño, por vía ascendente la leche se contamina por bacterias que se adhieren a la piel de la ubre y posterior al ordeño entran a través del esfínter del pezón (staphilococcus aureus, streptococcus, coliformes). Por vía descendente o hematógena lo utilizan los microorganismos que pueden causar enfermedades sistémicas o tienen la propiedad de movilizarse por la sangre a través de los capilares mamarios llegando a infectar la ubre (salmonellas, brucellas, mycobacterium tuberculosos). Por medio externo se tiene las malas prácticas de ordeño evidenciadas en todas las cuencas de estudio, existiendo carencia de establos o lugares adecuados de ordeño, ausencia de higiene en ubres y pezones, exposición de la leche durante un período largo de tiempo hasta la finalización del ordeño. En general podríamos decir que la calidad higiénica de la leche en la región de Puno es deficiente, comparado con la leche del sur de México reportado por Álvarez-Fuentes (2012) con 13,152ufc/ml en épocas secas y 7,220ufc/ml en épocas de lluvia. El agua contaminada y otros elementos del medio también son influyentes en estos aspectos higiénicos como las plagas, insectos y roedores, tal como lo explica también la revista Tecnología Productiva de Lácteos (2012).

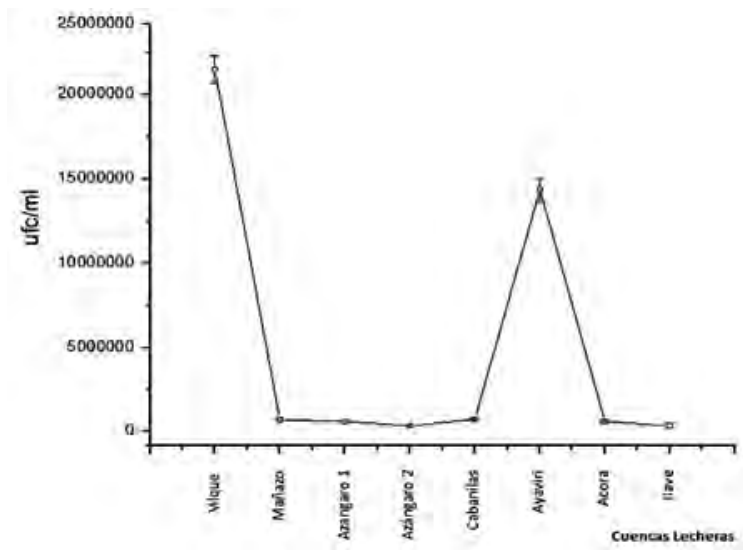

Figura 1. Conteos de bacterias Mesofílicas aerobias en ocho cuencas de la región Puno (expresadas como unidades formadoras de colonias por mililitro: ufc/ml). 


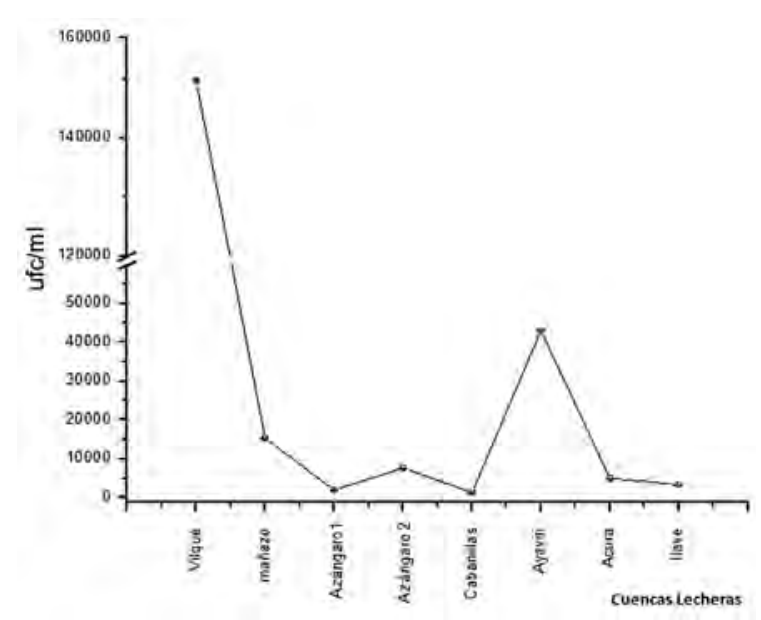

Figura 2. Conteos de Escherichia Coli en las cuencas de la región Puno (expresadas como unidades formadoras de colonias por mililitro: ufc/ml).

\section{Análisis pesticidas}

Los resultados de los análisis toxicológicos, realizados para los cuatro grupos de pesticidas, resultaron negativos en concentración de 1,0 ug/gr de muestra, sin embargo, los LMR de la mayoría de los pesticidas son menores a esta concentración; por tanto, solo podríamos referirnos a aquellos que no superan la concentración trabajada en las normas del codex. En cuanto a este estudio, podemos referir que debido a su naturaleza lipolítica y relativa estabilidad, la mayoría de los insecticidas clorados, fosforados y sus metabolitos son eliminados al exterior a través de la leche. La velocidad de excreción en la leche depende, entre otros, del estado de lactación, volumen de grasa producida al día, raza, naturaleza del pesticida, cantidad ingerida al día, duración de la ingestión, entre otros (Magariños, 2000).

La llegada de los pesticidas desde el medio ambiente a la leche puede producirse por diferentes vías: Lucha contra parásitos en salas de ordeño y dependencias anexas, pudiendo quedar el equipo de ordeño y las paredes contaminadas, los que a su vez contaminan la leche y los tratamientos directos al animal, además de la lucha contra plagas en suelos y cultivos. La Comisión del Codex Alimentarius, establecido por la FAO y la OMS en 1963, elaboró normas, directrices, códigos de prácticas alimentarias internacionales armonizadas, destinadas a proteger la salud de los consumidores y asegurar prácticas equitativas en el comercio de los alimentos, dentro de lo establecido encontramos los límites máximos permisibles (LMR) para los grupos de pesticidas como son organoclorados, organofosforados, carbamatos y piretroides, los cuales se muestran en la tabla 4 y 5 .

Los pesticidas que cumplirían con las normas establecidas son: dicofol, (Organoclorado), acefato, pirimifos-metil, fention, dimetoato (Organofosforado), carbarilo, bendiocarb, carbofuran, propoxur (carbamato) y fenpropatrin, bifentrin, permetrin, fenvalerato, cipermetrin (Piretroides). Es posible que los demás pesticidas cumplan los estándares por el hecho de que el ganado se alimenta de pastoreo natural, los cuales se encuentran alejados de las extensiones de cultivos, además de ello en los meses de estudio en la región Puno no fue época de fumigación en los sembríos. Sin embargo, esto obedece a un estudio cuantitativo de residuo de pesticidas por cromatografía de gases para tener resultados más precisos.

Tabla 4

FAO/OMS niveles máximos permisibles para insecticidas organoclorados y organofosforados en leche $(\mathrm{mg} / \mathrm{kg})$

\begin{tabular}{lcclcc}
\hline Organoclorados & LMR & LMR * $\mathbf{2 5}$ & Organofosforados & LMR & LMR * 25 \\
\hline Heptacloro & 0,006 & 0,15 & Profenofos & 0,01 & 0,25 \\
DDT & 0,02 & 0,5 & Oxidemeton-metil & 0,01 & 0,25 \\
Clordano & 0,002 & 0,05 & Triazofos & 0,01 & 0,25 \\
Aldrin y Dieldrin & 0,006 & 0,15 & Fosmet & 0,02 & 0,5 \\
Lindano & 0,01 & 0,25 & Metamidofos & 0,01 & 0,25 \\
Endosulfan & 0,004 & 0,1 & Acefato & 0,1 & 2,5 \\
Dicofol & 0,1 & 2,5 & Clorpirifos-metil & 0,01 & 0,25 \\
& & & Pirimifos-metil & 0,05 & 1,25
\end{tabular}




\begin{tabular}{llcc} 
& Disulfoton & 0,01 & 0,25 \\
& Monocrotofos & 0,002 & 0,05 \\
& Metidation & 0,001 & 0,025 \\
& Fention & 0,05 & 1,25 \\
& Fenitrotion & 0,002 & 0,05 \\
& Dimetoato & 0,05 & 0,25 \\
\hline
\end{tabular}

Fuente: FAO/OMS Normas alimentarias- Comité del CODEX ALIMENTARIUS, 2000 Límites Máximos del Codex para Residuos/Límites Máximos del Codex para Residuos Extraños Presentes en la Leche y los Productos Lácteos. LMR * 25 (contenido de grasa mayor al 2\%)

Tabla 5

FAO/OMS niveles máximos permisibles para insecticidas carbamatos y piretroides en leche $(\mathrm{mg} / \mathrm{kg})$.

\begin{tabular}{lccccc}
\hline Carbamatos & LMR & LMR $* 25$ & Piretroides & LMR & LMR*25 \\
\hline Bendiocarb & 0,05 & 1,25 & Fenpropatrin & 0,1 & 2,5 \\
Aldicarb & 0,01 & 0,25 & Bifentrin & 0,05 & 1,25 \\
Carbofuran & 0,05 & 1,25 & Ciflutrin & 0,01 & 0,25 \\
Metomilo & 0,02 & 0,5 & Deltametrin & 0,02 & 0,5 \\
Propoxur & 0,05 & 1,25 & Permetrin & 0,1 & 2,5 \\
Carbarilo & 0,1 & 2,5 & Fenvalerato & 0,1 & 2,5 \\
& & & Cipermetrin & 0,05 & 1,25 \\
\hline
\end{tabular}

Fuente: FAO/OMS Normas alimentarias- Comité del CODEX ALIMENTARIUS, 2000 Límites Máximos del Codex para Residuos/Límites Máximos del Codex para Residuos Extraños Presentes en la Leche y los Productos Lácteos. LMR * 25 (contenido de grasa mayor al 2\%).

\section{Conclusión}

El análisis físico-químico de la leche en las cuencas estudiadas mostró que el 50\% contiene baja proteína y grasa. El tenor de proteína registrada en el 50\% de cuencas no cumple con la Norma Oficial Mexicana. NOM-155-SCFI-2012 y guardan relación con el bajo porcentaje de lactosa, asimismo, se observó que los altos niveles de proteína coincidieron con una mayor concentración de sólidos totales y con una mayor densidad. La acidez presentada en la mayoría de cuencas sobrepasa la NTP 201.001.2003 que tiene relación directa con el $\mathrm{pH}$.

La mayoría de las cuencas lecheras se encuentran dentro de los estándares de las normativas vigentes peruanas y mexicanas, sin embargo, las cuencas de Azángaro 1, Mañazo, Ayaviri e Ilave presentan una mejor calidad, alcanzando una clasificación A según la normativa mexicana.
La calidad higiénica de leche presentó un alto contenido bacteriano en mesofilos de dos cuencas (Vilque y Ayaviri) y en E. Coli ninguna cuenca reportó conteo dentro de la norma estipulada, estos datos obedecen a las malas prácticas de ordeño y condiciones ambientales precarias. Los resultados de residuos de pesticidas en concentración de 1,0 ug/g de muestra fueron negativos, esto se relaciona con la ausencia de cultivos cercanos a las áreas de pastoreo y la ausencia de fumigación en esta época del año (setiembre-octubre), sin embargo, el estudio cuantitativo de estos compuestos químicos daría una mayor vislumbre de la contaminación que podría existir en este ámbito.

En la región Puno existe un desconocimiento de la calidad físico-química y microbiológica de la leche fresca, y siendo una de las zonas productoras importantes en el Perú, es de vital importancia que se evalúe estos aspectos fundamentales para la competitividad productiva de la ganadería peruana como también 
para su consumo garantizado. Como punto de partida los resultados de este estudio alertan a los organismos agropecuarios del sector lácteo, los cuales podrían implementar programas de control, asesoramiento y capacitaciones para los ganaderos de esta región, de esta manera fortalecer la capacidad para obtener la admisibilidad de la leche a mercados más exigentes.

\section{Agradecimientos}

Los autores desean expresar agradecimiento al Proyecto Especial Binacional Lago Titicaca quien tuvo a cargo la coordinación con los ganaderos y el acompañamiento de muestreo en las cuencas de estudio. Al laboratorio de CICOTOX de la Universidad Nacional de San Marcos donde fueron realizados los análisis de residuos de pesticidas, igualmente al Ing. Oli Morales Sacaca por el apoyo del equipo Ultrasónico de PROYECTO PRADERA- Puno con fines analíticos para el presente estudio.

\section{Referencias}

Álvarez-Fuentes, G.; Herrera-Haro, JG.; Alonso-Bastida, G.; Barreras-Serrano, A. (2012). Calidad de la leche cruda en unidades de producción familiar del sur de Ciudad de México. Archivos de Medicina Veterinaria, 44(3): 237-242.

AOAC. (1990). Official Methods of Analysis. Edición Quince. Association of Official Analytical Chemists. Airlongton.

Arriaga, JC. (1996). Estrategias de Alimentación de Bovinos Lecheros en Sistemas de Producción en Pequeña Escala. En: Castelán O O A, comp. Estrategias para el mejoramiento de los sistemas de producción de leche en pequeña escala. Universidad Autónoma del Estado de México. pp 45-68.

Bernal Martínez, L. R.; Rojas Garduño, M. d. l. Á.; Vázquez Fontes, C.; Espinoza Ortega, A.; Estrada Flores, J.; Castelán Ortega, O. A. (2007). Determinación de la calidad fisicoquímica de la leche cruda producida en sistemas campesinos en dos regiones del Estado de México. Veterinaria México 38(4): 395-407.

Chamberlain, AT.; Wilkinson, JM. Feeding the Dairy Cow. Lincoln (UK) (2002). Chalcombe Publications.

COFOCALEC, AC. (2009). Guía para la interpretación de resultados de análisis de leche. Programa lechero. México Dhaliwal, GS. (1990). Pesticide contamination of milk and milk products. Offprints from food contamination from environmental products. John Wiley and Sons, Inc., New York.

FAO/ OMS (2006). Pesticide residues in food. Maximum residue limits. Secretariat of the Codex Alimentarius Commission. Roma, Italia. Recuperado de: http://www. codexalimentarius.net/mrls/pestdes/jsp/pest_q-e.js.
Federación Panamericana de Lechería (2011). Curso de capacitación "Calidad e inocuidad en fincas Lecheras". FEPALE-Uruguay.

Fernícola, N. (1985). Toxicología de los insecticidas organoclorados. Bol. Of. San. Panam. 98 (1): 10-18.

Flores, A. (2001). Producción lechera en la irrigación Majes- Arequipa un sistema de alimentación para vacas lecheras en áreas de irrigación. Rev Inv. Vet Perú; 12(2):14-20.

Fong, G.; Moye, A.; Seiber, J.; Toth, J. (1999). Pesticides Residues in Foods Methods. Techniques and Regulations. New York. John Wiley \& Sons, Inc. pp 1-101.

Gallardo, M. (2003). Alimentación y composición de la leche. Memorias del Seminario Mercoláctea; mayo 10; San Francisco (Córdoba) Argentina. San Francisco (Córdoba) Argentina: Instituto Nacional de Tecnología Agropecuario (INTA) Rafaela, 2003:1:16.

Gómez, JM.; Correa, G.; Barahona R. (2014). Evaluación del residuo del cultivo de agaricus bisporus como alimento de vacas lecheras en lactancia media. Revista Facultad Nacional de Agronomía. ISSN 0304-2847

Goutner, V.; Albanis, T.; Konstantinou, I.; y Papakonstantinou, K. (2001). PCBs and organochlorine pesticide residues in eggs of audouins gull (Larus audouinii) in the North-Eastern Mediterranean. Mar pollut. bull. 42:377-388.

Hernández, GM.; Jiménez, GC.; Jiménez, AF.; Arceo. GM. (2007). Caracterización de las intoxicaciones agudas por plaguicidas: Perfil ocupacional y conductas de uso de agroquímicos en una zona agrícola del Estado de México, México. Rev. Int. Contam. Ambient. 23: 159167.

Hernández, HY.; Pérez B.M.E. (1995). El vuelo del mosquito: un debate sobre mosquitos, Avance y perspectiva. 14: 5-15. CINVESTAV, México

Hernández, R, Ponce, P. (2002). Composición de la leche en las condiciones actuales del trópico en Cuba. Rev. Salud Anim. 24 (2) 111-114

Inventario Nacional de Plaguicidas COP. (2006). Plan nacional de implementación del convenio de Estocolmo sobre los contaminantes orgánicos persistentes en el Perú. Proyecto GEF/PNUMA Nº GFL-2328 - 27614747.

Juan, A.; Picó, Y.; Font, G. (2003). Revisión de los métodos de determinación de residuos de plaguicidas organofosforados en alimentos. Rev. Toxicol. 20: 166-175.

Langer, P. (2003). Possible effects of polychlorinated biphenyls and organochlorinated pesticides on the thyroid after long-term exposure to heavy environmental pollution. Joem 45:526.

López, L.; Torres, L.; Espinosa, F.; Jiménez, C.; Cebrián, M.; Waliszewski, K.; Saldate, O. (1996). Is DDT use a public health problem in México. Environ. Health Perspect. 104 (6): 584-588. 
Magariños, H. (2000). Producción higiénica de la leche cruda. Una guía para la pequeña y mediana empresa. Capítulo X: Contaminación por pesticidas. Guatemala. Recuperado de: http://www.science.oas.org/ oea_gtz/LIBROS/LA_LECHE/leche_all.pdf

Mamani, J. (2009). Calidad de Leche: Resultados de Análisis de Muestras de Leche en Majes. Laboratorio de calidad de leche cruda COZOPROPLE-PIMS.

Medina, C. (2010). Residuos de insecticidas organoclorados en yogurt firme de tres marcas comerciales, elaborado en Venezuela Rev. cient. Maracaibo 20 (2)

Ministerio de Agricultura y Riego (2014). Oficina de estudios ecocnómicos y estadisticos-OEE. Revista mes de Mayo.

Murcia, A.; Stashenko, E. (2008). Determinación de plaguicidas organofosforados en vegetales producidos en Colombia. AGRO SUR 36(2) 71-81

NMX-F-700-COFOCALEC (2012). Sistema Producto Leche-Alimento-Lácteo-Leche cruda de vaca- Especificaciones fisicoquímicas, sanitarias y métodos de prueba.

NORMA TÉCNICA PERUANA. NTP 202.001 (2003). Comisión de Reglamentos Técnicos y Comerciales INDECOPI. Lima, Perú.

Pérez, A. et al. (2009). Residuos de plaguicidas organofosforados en cabezuela de brócoli (brassica oleracea) determinados por cromatografía de gases. México. Rev. Int. Contam. Ambient. 25 (2) 103-110.

Pinto, M.; Montes, L.; Anrique, R.; Carrillo, R.; Tamayo, R.; Cristi, R. (1990) Residuos de plaguicidas organoclorados en leche de vaca y su relación con alimentos para uso animal como fuentes de contaminación, Arch. Med. Vet. 22 (2): 143-153.

Pitarch, AE.; López, FJ.; Serrano, R.; Hernández, F. (2001). Multiresidue determination of organophosphorus and organochlorine pesticides in human biological fluids by capillary gas chromatography. Fresen. J. Anal. Chem. 369, 502-509.

Plan de implementación de la estrategia de competitividad cadena productiva de productos lácteos (2014). Gobierno Regional Puno.

Plan nacional de implementación del convenio de Estocolmo sobre los contaminantes orgánicos persistentes en el Perú. Proyecto GEF/PNUMA Nº GFL-2328 - 2761 $-4747$.

Preston, TR.; Leng, RA. (1987). Matching ruminant production systems with available resources in the tropics and sub-tropics. New South Wales (Australia): Penambul Books Armidale.

Proyecto Especial Binacional del Lago Titicaca (2012). Diagnóstico situacional: Mejoramiento de los sistemas de producción de vacunos lecheros en los distritos de Cabana, Cabanillas, Cabanilla, Mañazo, Vilque,
Acora e Ilave en la región Puno. Proyecto Lácteos PELT Puno Perú.

Proyecto Pradera (2013). Programa regional de apoyo al desarrollo rural andino. Gobierno Regional Puno.

Rodriguez, L.M.H.; Loyola, E.E.G.; Betanzos, R.A.F.; Villarreal, T.C.; Nielsen, B.D. (1994). Control focal del paludismo. Tratamiento focal usando quimioprofilaxis y rociado intradomiciliario con insecticida para el control del paludismo en el sur de México. Gaceta Médica de México 130 (5): 313-319.

Santos, A. (1998). Leche y sus derivados. Editorial Trillas S.A. México (DF).

Secretaría de Comercio y Fomento Industrial. (2003) Norma Oficial Mexicana NMX-BB-085-1982. México (DF): Secretaría de Economía (SE)

Servicio Nacional de Sanidad Agraria. Consejo Nacional del Ambiente. Dirección General de Salud Ambiental (2007) Plan Nacional de Implementación del Convenio de Estocolmo sobre los Contaminantes Orgánicos Persistentes en el Perú. Proyecto GEF/PNUMA. Lima: SENASA/ CONAM/DIGESA.

Situación de la lechería en América latina y el caribe (2011). Informe producido en el ámbito del observatorio de la cadena láctea de América Latina y el Caribe. Organización de las Naciones Unidas para la Alimentación y la Agricultura (FAO). Federación panamericana de lechería (FEPALE).

Spreer, E. (1991). Lactología industrial. Editorial Acribia S.A. Zaragoza, España.

Tecnología productiva en lácteos (2012). Calidad de la leche. Solid OPD Organización Privada de Desarrollo: Proyectos lácteos. Revista de Leche Peruana.

Waliszewski, SM.; Infanzón, RM. (2003). Diferencia entre concentraciones de plaguicidas organoclorados persistentes en suelo, paja y granos de trigo. Rev. Int. Contam. Ambient. 19: 5-11.

Weber, J.B. (1997). The pesticida scorecard. Environmental science and Technology. 11: 756-776.

Yamandú, A. (2002). Calidad de leche: Alimentación y rendimiento de sólidos. Instituto Nacional de Investigación Agropecuaria. Jornada de lechería 10 años de actividades del laboratorio de Calidad; 2002 junio 11. La Estanzuela (Colonia) Uruguay: Serie de actividades de Difusión $N^{\circ}$ 287:49-57.

Zegarra, J.; Díaz, G.; Vélez, V.; Torres, J. (2007). Efecto del uso de concentrados con carbohidratos de diferente degradabilidad rumial sobre el balance de nitrógeno en vacas lecheras bajo pastoreo de alfalfa. APPA- ALPA. Asociación Latinoamericana de Producción Animal. 